\title{
The role of Candida species in peri-implant diseases
}

\section{Igor Smojver ${ }^{1}$, Marko Vuletić², Mato Sušić ${ }^{2}$ Luka Marković ${ }^{3}$, Ivica Pelivan ${ }^{4}$, and Dragana Gabrić ${ }^{2}$}

1. Private Dental Clinic, Zagreb, Croatia

2. Department of Oral Surgery, School of Dental Medicine, University of Zagreb, Croatia

3. Department of Periodontology, School of Dental Medicine, University of Zagreb, University Hospital Center Zagreb, Croatia

4. Department of Prosthodontics, School of Dental Medicine, University of Zagreb, Croatia

\section{REVIEW}

Please cite this paper as: Smojver I, Vuletić $M$, Sušić $M$, Marković L, Pelivan I, Gabrić D. The role of Candida species in peri-implant diseases. AMJ 2020;13(3):98-105.

https://doi.org/10.35841/1836-1935.13.3.98-105

Corresponding Author:

Marko Vuletić DMD, PhD

Department of Oral Surgery, School of Dental Medicine, University of Zagreb

Gundulićeva 5, Zagreb, Croatia

Email: mvuletic@sfzg.hr

\section{ABSTRACT}

\section{Background}

Peri-implantitis is a chronic, marginal and progressive infection of soft and hard tissue that surrounds dental implants, which results in the loss of the supporting bone, caused by similar microbes as adult periodontitis. Staphylococcus aureus and Candida albicans are microorganisms that are not primarily associated with periodontitis, but certain studies identified them in periimplant pockets.

\section{Aims}

The current review aimed to assess the role of Candida species in peri-implant diseases.

\section{Methods}

This review has been carried out in accordance with the question: "What is the role of Candida albicans in periimplant diseases?". To answer this, a bibliographic search was carried out using PubMed, Scopus and Medline and it was limited to works published during 2009-2019.

\section{Results}

Candida albicans appears to play an important role in the formation and stabilization of biofilm on the titanium surfaces and in the implant itself, which subsequently allows the growth of periodontal pathogenic bacteria involved in the development of inflammatory response resulting in the loss of bone supporting the dental implant.

\section{Conclusion}

Further research is needed to shed more light on the pathophysiology of peri-implant inflammation and to find more effective ways to treat it.

\section{Key Words}

Peri-implantitis, periodontitis, biofilm, microorganisms, Candida albicans

\section{What this study adds:}

\section{What is known about this subject?}

The entry of microorganisms that are commonly resident in the oral cavity into the implant microgap might promote the formation of a biofilm in the implant itself. The biofilm acts as a reservoir of microorganisms that may lead to implant failures.

\section{What new information is offered in this study?}

Candida albicans appears to play an important role in the formation and stabilization of biofilm on the titanium surfaces and in the implant itself, resulting in the loss of bone supporting the dental implant.

3. What are the implications for research, policy, or practice?

There is a need for further research to shed more light on the pathophysiology of peri-implant inflammation and to find more effective ways to treat it. 


\section{Background}

Dental implantology is a part of oral surgery, which is widely used to replace missing teeth. In the $21^{\text {st }}$ century, improvements in surgical protocol, design and surface made this kind of dental therapy highly secure and predictable with a mean survival rate of 94.6 per cent and a mean success rate of 89.7 per cent during follow-up in the period of 10 years ${ }^{1}$ The failure of implant therapy can be a result of biological or mechanical issue. Chronological failure is divided in two parts, early and late. Early complications are repercussion of surgical trauma, bone infection/contamination and a lack of primary stability or small bone volume, while late complications are the result of microbiological changes, such as peri-implantitis or biomechanical changes such as occlusal overload. ${ }^{2}$

The connection between implant and abutment is the most concerning part in implant therapy because from a mechanical point of view it represents the weakest point, and from a biological point a micro-gap can cause a leakage of microbes. The micro-gap is a small space between implant and abutment, which can often be a reservoir for different types of commensal and pathogenic bacteria, specially micro-aerophilic or anaerobic species. These microbes lead to tissue inflammation and progression results in bone resorption. ${ }^{3,4}$

Peri-implantitis (Figure 1 ) is a chronic, marginal and progressive infection of soft and hard tissue that surrounds dental implants, which results in the loss of the supporting bone, caused by similar microbes as adult periodontitis, such as Campylobacter rectus, Aggregatibacter actinomycetemcomitans, Prevotella nigrescens and Enteric bacilli. ${ }^{5,6}$ Staphylococcus aureus and Candida albicans are microorganisms that are not primarily associated with periodontitis, but certain studies identified them in periimplant pockets. ${ }^{7,8}$

Colonies by the genus Candida spp. were found in periodontal pockets, periodontitis and implant failure in the study of Reynaud et al. ${ }^{9}$ and Dahlen et al. ${ }^{10}$ Candida albicans as a commensal is the major pathogen in oral and systemic candidiasis and the prime fungus in the oral cavity of 20-40 per cent of healthy individuals. ${ }^{11}$ It is regarded as a major human pathogen in clinical studies, and the frequency of cutaneous and mucosal fungal infection has increased during recent years. Opportunistic infections in immunosuppressed patients and polytrauma patients with damaged barriers are typical for the development of candidiasis. ${ }^{12}$ Nosocomial infections in the United States caused by candidiasis are ranked as even more common than some bacteria. The reason for this data is in an increased use of antibiotics, more invasive therapeutic medical procedures and an increasing number of seriously ill patients and immunosuppresive therapies. ${ }^{13}$

\section{Method}

This work has been carried out in accordance with the Preferred Reporting Items for Systematic Reviews and Meta-Analyses (PRISMA) statement.

This review has been carried out in accordance with the question: "What is the role of Candida albicans in periimplant diseases?". To answer this, a bibliographic search was carried out using PubMed, Scopus and Medline and it was limited to works published during 2009-2019. The keywords used for the search were "dental implant", "periimplantitis" and "Candida".

The inclusion criteria for the research literature were articles published in the last 10 years and that were written in English with full texts available. There were no exclusion criteria because there is a lack of literature on this issue.

All the information were obtained from the articles selected by one of the authors [MV].

\section{Results}

A systemic research of the databases was carried out with the following research strategies:

"dental" [All Fields] AND "implant" [MeSH Terms] OR "dental implant" [All Fields] AND "peri-implantitis" [MeSH Terms] OR "peri-implant" [All Fields] AND "disease" [All Fields] AND "fungi" [All Fields] AND "Candida" [MeSH Terms] OR "Candida" [All Fields] AND "peri-implant disease" [All Fields] AND "Candida" [All Fields] OR "Candida" [MeSH Terms] OR "peri-implantitis" [All Fields] AND "Candida albicans" [All Fields] AND "2009" [PDat] AND "English" [lang].

A total of 49 articles were found, out of which, after reading the title and abstract, 27 were excluded for not complying with the established criteria of the role of Candida species in peri-implant diseases; 22 articles were selected and analysed (Figure 2).

\section{Discussion}

\section{Oral biofilm}

The process of oral biofilm development has five phases: 1) adhesion to soft and hard tissues (polysaccharides and adhesins); 2) growth (matrix formation); 3) maturation 
(metabolic and genetic microbial exchanges); 4) tissue destruction (enzymes and toxic metabolites); and 5) surface detachment. ${ }^{14,15}$

Organic salivary compounds are adsorbed to soft tissue or hard tissue surfaces, such as dentin, enamel, calculus, prosthetic materials or resorative, and then they produce receptors for early colonizers. Initial adhesion stage of bacteria lasts for a few seconds and is reversible. ${ }^{16,17}$ The growth and maturation of biofilm can take hours or days depending on environmental conditions and types of microbes. Fungi and bacteria form aggregates that are confluent. ${ }^{18}$ In mature biofilm there are aggregates of microorganisms growing with an extracellular matrix, which consists of dead microbial and host cells, metabolites, collagen, salivary components and some drugs. The matrix is crossed by multiple channels with nutrients, oxygen and metabolites, and it is also very well hydrated. ${ }^{19}$ Oxygen availability and metabolic interactions are responsible for the biofilm maturation, Candida albicans in combination with Streptococcus oralis increase formation of biofilm. ${ }^{20}$ In early childhood caries, the presence of $C$. albicans increases the virulence of $S$. mutans and results in rapid growth of caries lesions. Willems et al. ${ }^{21}$ reported that during the growth of $S$. mutans and lactate production, environmental $\mathrm{pH}$ is increased by Candida above critical value, while $\mathrm{Ca}^{2}+$ release from hydroxyapatite disks is inhibited by the presence of this fungi. The invasion and destruction of soft tissue is caused by different enzymes, such as proteases, nucleases, lipases and ureases which can be triggered by Candida. The invasion and destruction of hard dental tissues begins with decalcification of the hydroxyapatite crystals of enamel and dentin, followed by enzymatic lysis of organic parts of hard tissues. ${ }^{22,23}$ The biofilm of a healthy adult is moistened by saliva flow of approximately $0.35 \mathrm{ml} / \mathrm{min}$, which is responsible for providing nutrients, mucus membrane, elimination of some bacteria and for buffering the $\mathrm{pH}$ which results in remineralisation of hard tooth surface. ${ }^{24,25}$ The late stage in process of biofilm development is the detachment of microbial aggregates or cells. It depends on suport, microbial community, nutrient availability, physical-chemical conditions and hydrodynamics influenced by environment. Candida albicans produces glucanases which causes lysis of extracellular polymers and in the end the microbial aggregate detachment. ${ }^{26,27} \mathrm{C}$. albicans is to date the most common species used in oral consortium studies as it is most amenable to identification, culture and isolation. Bertolini et al. ${ }^{28}$ used three stains of mutant $C$. albicans, while Pereira-Cenci et al. ${ }^{29}$ described a model with Candida glabrate and albicans. In a recent study, ${ }^{30}$ a model of vulvovaginal candidiasis was developed containing Candida glabrata in combination with two probiotic lactobacilli, Lactobacillus rhamnosus and Lactobacillus router.

\section{Histopathology of peri-implant disease}

Biological complications of dental implants are a major problem in contemporary dentistry. Peri-implantitis is a destructive inflammatory process caused by the bacterial colonization of peri-implant tissues ${ }^{31}$. It affects the soft and hard tissues around implants and is characterized by the formation of a peri-implant pocket formation and bone resorption (Figure 3). Clinically, soft tissue inflammation is detected by probing (bleeding on probing, BOP) (Figure 4), while progressive bone loss is identified on radiographs. ${ }^{32}$

There are two clinical and histological entities: peri-implant mucositis and peri-implantitis. Peri-implant mucositis is assumed to precede periimplantitis. ${ }^{33}$ The conditions characterizing the conversion from peri-implant mucositis to peri-implantitis have not been identified.

The peri-implant soft tissue reactions to plaque formation have been extensively evaluated in animal and human studies alike. ${ }^{34,35}$ Plaque formation resulted in an inflammation of the peri-implant soft tissues, associated with the clinical signs of inflammation, such as redness and edema. $^{36}$

When compared to peri-implant mucositis, the lesions at peri-implantitis sites harboured more neutrophil granulocytes and larger "proportions of B cells (CD19+)".$^{37}$ Similarly to periodontitis, the lesions at peri-implantitis sites are dominated by plasma cells and lymphocytes. ${ }^{38-40}$ but are characterized by larger proportions of polymorphonuclear leukocytes and macrophages. ${ }^{41}$ The size of peri-implantitis lesions is more than twice as large as the one noted at periodontitis sites according to Carcuac et al. ${ }^{42}$ Another study using immunohistochemical analysis of harvested soft tissue biopsies showed that IL-1 $\alpha$ was a dominant osteoclast activating cytokine at peri-implantitis sites. ${ }^{43}$

\section{Microbiology of peri-implantitis}

When compared with healthy implant sites alone, periimplantitis was associated with higher counts of 19 bacterial species including Porphyromonas gingivalis, Prevotella intermedia, Fusobacterium nucleatum and Aggregatibacter actinomycetemcomitans. ${ }^{44}$ Studies have indicated that periimplantitis was more frequently linked with opportunistic pathogens, such as Pseudomonas aeruginosa and Staphylococcus aureus ${ }^{45,46}$ fungal organisms like Candida 
albicans ${ }^{45,47,48}$ and viruses (i.e. human cytomegalovirus, Epstein-Barr virus). ${ }^{49}$

In case of dental implants, there is a colonization of their external surfaces and at the interface of the implant and the prosthetic abutment connection, ${ }^{50}$ in the micro-gap formed between the implant and the prosthetic abutment. Microorganisms colonizing the outer surface can be eliminated by the host defence mechanisms, but the microorganisms that internally colonize the implants and the interfaces of the parts can persist for long periods, causing unpleasant odour and taste, infections, and tissue damage. ${ }^{51}$

In vivo and in vitro studies have demonstrated the presence of viable microorganisms in internal parts of the implants and the infiltration of fluids and microorganisms throughout their internal space, which may lead to contamination of the tissues near the inserted dental implants. ${ }^{52,53}$

\section{Candida species role in peri-implant infections}

Candida spp yeasts are an important component of the resident microbial ecology of the oral cavity, as they are frequently associated with the formation of biofilm on implantable medical devices including dental implants. ${ }^{54}$ Candida glabrata represents an emerging species of non albicans Candida and is small yeast [yeast-like cells or blastoconidia, $2.0-4.0 \quad 3 \quad 3.0-5.5 \mathrm{~mm}$ in size]. The introduction of artificial materials into bodily locations has been accompanied by the ability of microorganisms, including Candida spp, to colonize them and form biofilms that protect them from antibiotic diffusion and host defences, leading to persistent infections. ${ }^{55}$ Moreover, the biofilms, which are complex 3-dimensional structures, can coaggregate and/or bind to bacteria already colonizing these devices. ${ }^{56}$

C. albicans virulence refers to its ability to produce hyphae, secrete hydrolytic enzymes, activate inflammatory responses and invade tissues. ${ }^{57,58}$ They are controlled through several genes, such as hyphal wall protein (HWP), phospholipases $(P L)$, agglutinin-like sequences $(A L S)$ and aspartyl-proteinases $(S A P) .{ }^{59}$ the development of hyphae and virulence gene expression may be modulated by local environmental factors including gaseous atmosphere and nutrient content. ${ }^{60,61}$

Dental plaque has a high microbial density with around 700 oral bacterial species which could be isolated and grown in vitro, and an individual often has 100 or more cultivable bacterial strains in his or her oral cavity. ${ }^{62}$ Similarly, oral microbiome has more than 100 fungal species, most of which are noncultivable. ${ }^{63}$ In several studies, ${ }^{64,65}$ animal models have been used to mimic oral microcosm, but the problem was that animal ecosystems are different from those in humans. Some biofilm models are grown with human epithelial cell cultures to be closer to in vivo conditions. ${ }^{24}$ Many of noncultivable species may play a role in health and disease, so that Candida albicans and prominent periodontopathogens were not always present in caries, periodontitis or candidiasis. ${ }^{63,66,67}$

Yeasts can adhere to non-biological surfaces, besides adherence to teeth and oral mucosal surfaces, such as dental materials as dental implants. ${ }^{68,69}$ An experimental study $^{69}$ showed that Candida albicans biofilm is thicker on the body surfaces of bone-level and tissue-level implants compared to abutments and cover screws. In the case of peri-implant biofilms it was hypothesized that a similar phenomenon would occur with the bacterial population, also impacting on C. albicans virulence.

The contribution of oral yeasts in the occurrence and progression of peri-implant diseases is still unclear, although it is known that Candida species in subgingival oral biofilm contributes to aggressive and chronic periodontitis. ${ }^{70}$

The entry of microorganisms that are commonly resident in the oral cavity into the implant microgap might promote the formation of a biofilm in the implant itself. The biofilm acts as a reservoir of microorganisms which may lead to implant failures. In the study of Baggi et al., ${ }^{52}$ it was observed that the implant-abutment unit with the platform-switched interface was more resistant to colonization and the consequent eventual biofilm formation after the exposure to Streptococcus and C. albicans. The ability of the conical connection geometry to resist the entry of $C$. albicans compared with the flat-to-flat geometry is noteworthy considering the high tendency of Candida spp to colonize medical devices. ${ }^{71}$ Candida glabrata is dimensionally smaller than C. albicans. Silva et al. ${ }^{72}$ reported that C. glabrata exhibits a degree of hydrophobicity comparable with that of C. albicans, although only a few studies have evaluated the role and pathogenicity of $C$. glabrata in the formation of biofilm on medical devices.

\section{Conclusion}

Peri-implantitis is a multimicrobial, multifactorial infectious disease of soft tissues and bone around dental implants, but without standardized treatment modality. Preventive treatment measures exist, but they are not standardized or 
scientifically established over standard implant-prosthetic rehabilitation protocols.

Candida albicans appears to play an important role in the formation and stabilization of a biofilm on titanium surfaces and in the implant itself, which subsequently allows the growth of periodontal pathogenic bacteria involved in the development of inflammatory response resulting in the loss of bone supporting the dental implant. Further research is needed to shed more light on the pathophysiology of periimplant inflammation and to find more effective ways to treat it.

\section{References}

1. Moraschini V, Poubel LA, Ferreira VF, et al. Evaluation of survival and success rate of dental implants reported in longitudinal studies with a follow-up period of at least 10 years: a systematic review. Int J Oral Maxillofac Surf. 2015;44:377-88.

2. Schmitt CM, Nogueira-Filho G, Tenenbaum HC, et al. Performance of conical abutment [Morse Taper) connection implants: a systematic review. J Biomed Mater Res A. 2014;102:552-74.

3. Mencio F, Papi P, Di Carlo S, et al. Salivary bacterial leakage into implant-abutment connections: preliminary results of an in vivo study. Eur Rev Med Pharmacol Sci. 2016;20:2476-83.

4. Brauner E, Guarino G, Jamshir S, et al. Evaluation of highly porous dental implants in postablative oral and maxillofacial cancer patients: a prospective pilot clinical case series report. Implant Dent. 2015;24:631-7.

5. Heitz-Mayfield LJ, Lang NP. Comparative biology of chronic and aggressive periodontitis vs. peri-implantitis. Periodontol 2000. 2010;53:167-81.

6. Checchi L, Gatto MR, Checchi V, et al. Bacteria prevalence in a large Italian population sample: a clinical and microbiological study. J Biol Regul Homeost Agents. 2016;30:199-208.

7. Maximo MB, De Mendonca AC, Renata Santos V, et al. Shortterm clinical and microbiological evaluations of periimplant diseases before and after mechanical antiinfective therapies. Clin Oral Implants Res. 2009;20:99-108.

8. Norowski PA Jr, Bumgardner JD. Biomaterial and antibiotic strategies for periimplantitis: a review. J Biomed Mater Res B Appl Biomater. 2009;288:530-43.

9. Reynaud AH, NygaardOstby B, Boygard GK, et al. Yeasts in periodontal pockets. J Clin Periodontol. 2001;28:8604.
10. Dahlen G, Wikstrom M. Occurrence of enteric rods, staphylococci and Candida in subgingival samples. Oral Microbiol Immunol. 1995;10:42-6.

11. Blankenship JR, Mitchell AP. How to build a biofilm: A fungal perspective. Curr Opin Microbiol. 2006;9:588-94.

12. Perlroth J, Choi B, Spellberg B. Nosocomial fungal infections: Epidemiology, diagnosis, and treatment. Med Mycol. 2007;45:321-46.

13. Belazi M, Velegrake A, Fleva A, et al. Candidal overgrowth in diabetic patients: Potential predisposing factors. Mycoses. 2005;48:192-6.

14. Park SJ, Han K-H, Park JY, et al. Influence of bacterial presence on biofilm formation of Candida albicans. Yonsei Med J. 2014;55:449-58.

15. Rams TE, Degener JE, van Winkelhoff AJ. Antibiotic resistance in human chronic periodontitis microbiota. J Periodontol. 2014;85:160-9.

16. Periasamy S, Kolenbrander PE. Mutualistic biofilm communities develop with Porphyromonas gingivalis and initial, early, and late colonizers of enamel. J Bacteriol. 2009;191:6804-11.

17. Cavalcanti IMG, Ricomini Filho AP, Lucena-Ferreira SC, et al. Salivary pellicle composition and multispecies biofilm developed on titanium nitrided by cold plasma. Arch Oral Biol. 2014;59:695-703.

18. Mitchell KF, Zarnowski R, Sanchez H, et al. Community participation in biofilm matrix assembly and function. Proc Natl Acad Sci USA. 2015;112:4092-97.

19. Sandai D, Tabana YM, Ouweini AE, et al. Resistance of Candida albicans biofilms to drugs and the host immune system. Jundishapur J Microbiol. 2016;9:37-8.

20. Diaz PI, Xie Z, Sobue T, et al. Synergistic Interaction between Candida albicans and commensal oral streptococci in a novel in vitro mucosal model. Infect Immun. 2012;80:620-32.

21. Willems HM, Kos K, Jabra-RizkMA, et al. Candida albicans in oral biofilms could prevent caries. Pathog Dis. 2016;74:39.

22. Falsetta ML, Klein MI, Colonne PM, et al. Symbiotic relationship between Streptococcus mutans and Candida albicans synergizes virulence of plaque biofilms in vivo. Infect Immun. 2014;82:1968-81.

23. Xu $H$, Sobue $T$, Bertolini $M$, et al. Streptococcus oralis and Candida albicans synergistically activate $\mu$-Calpain to degrade E-cadherin from oral epithelial junctions. J Infect Dis. 2016;214:925-34.

24. Bertolini MM, Xu $H$, Sobue $T$, et al. Candidastreptococcal mucosal biofilms display distinct structural and virulence characteristics depending on growth conditions and hyphal morphotypes. Mol Oral Microbiol. 2015;30:307-22. 
25. de Moraes AP Barwaldt CK, Nunes TZ, et al. Effect of triazine derivative added to denture materials on a microcosm biofilm model. J Biomed Mater Res B Appl Biomater. 2012;100:1328-33.

26. Jiao Y, Cody GD, Harding AK, et al. Characterization of extracellular polymeric substances from acidophilic microbial biofilms. Appl Environ Microbiol. 2010;76:2916-22.

27. El-Azizi M, Farag N, Khardori N. Antifungal activity of amphotericin B and voriconazole against the biofilms and biofilm-dispersed cells of Candida albicans employing a newly developed in vitro pharmacokinetic model. Ann Clin Microbiol Antimicrob. 2015;14:21.

28. Sobue T, Diaz $P, X u H$, et al. Experimental models of $C$. albicans-Streptococcal co-infection. Methods Mol Biol Clifton NJ. 2016;1356:137-52.

29. Pereira-Cenci T, Deng DM, Kraneveld EA, et al. The effect of Streptococcus mutans and Candida glabrata on Candida albicans biofilms formed on different surfaces. Arch Oral Biol. 2008;53:755-64.

30. Chew SY, Cheah YK, Seow HF, et al. In vitro modulation of probiotic bacteria on the biofilm of Candida glabrata. Anaerobe. 2015;34:132-8.

31. Mombelli A, Decaillet F. The characteristics of bio films in peri-implant disease. J Clin Periodontol. 2011;38:20313.

32. Lang NP, Berglundh T, Working Group 4 of Seventh European Workshop on P. Periimplant diseases: where are we now?-Consensus of the Seventh European Workshop on Periodontology. J Clin Periodontol. 2011;38:178-81.

33. Jepsen S, Berglundh T, Genco R, et al. Primary prevention of periimplantitis: managing periimplant mucositis. J Clin Periodontol. 2015;42:152-7.

34. Berglundh T, Lindhe J, Marinello $C$, et al. Soft tissue reaction to de novo plaque formation on implants and teeth. An experimental study in the dog. Clin Oral Implants Res. 1992;3:1-8.

35. Salvi GE, Aglietta M, Eick S, et al. Reversibility of experimental periimplant mucositis compared with experimental gingivitis in humans. Clin Oral Implants Res. 2012;23:182-90.

36. Schwarz F, Mihatovic I, Golubovic V, et al. Experimental periimplant mucositis at different implant surfaces. J Clin Periodontol. 2014;41:513-20.

37. Gualini F, Berglundh T. Immunohistochemical characteristics of inflammatory lesions at implants. J Clin Periodontol. 2003;30:14-8.

38. Sanz M, Alandez J, Lazaro P, et al. Histopathologic characteristics of periimplant soft tissues in Branemark implants with 2 distinct clinical and radiological patterns. Clin Oral Implants Res. 1991;2:128-34.

39. Cornelini R, Artese L, Rubini C, et al. Vascular endothelial growth factor and microvessel density around healthy and failing dental implants. Int J Oral Maxillofac Implants. 2001;16:389-93.

40. Bullon P, Fioroni M, Goteri $G$, et al. Immunohistochemical analysis of soft tissues in implants with healthy and periimplantitis condition, and aggressive periodontitis. Clin Oral Implants Res. 2004;15:553-9.

41. Berglundh T, Zitzmann NU, Donati M. Are periimplantitis lesions different from periodontitis lesions? J Clin Periodontol. 2011;38:188-202

42. Carcuac O, Berglundh T. Composition of human periimplantitis and periodontitis lesions. J Dent Res. 2014;93:1083-8.

43. Konttinen $Y T$, Lappalainen $R$, Laine $P$, et al. Immunohistochemical evaluation of inflammatory mediators in failing implants. Int J Periodontics Restorative Dent. 2006;26:135-41.

44. Persson GR, Renvert S. Cluster of bacteria associated with periimplantitis. J Periodontal Res. 2016;51:689-98.

45. Leonhardt A, Renvert S, Dahlen G. Microbial findings at failing implants. Clin Oral Implants Res. 1999;10:339-45.

46. Mombelli A, Decaillet $F$. The characteristics of biofilms in periimplant disease. J Clin Periodontol. 2011;38:203-13.

47. Schwarz F, Becker K, Rahn S, et al. Real time PCR analysis of fungal organisms and bacterial species at periimplantitis sites. Int J Implant Dent. 2015;1:9-16.

48. Albertini M, Lopez Cerero L, O'Sullivan MG, et al. Assessment of periodontal and opportunistic flora in patients with periimplantitis. Clin Oral Implants Res. 2015;26:937-41.

49. Jankovic S, Aleksic Z, Dimitrijevic B, et al. Prevalence of human cytomegalovirus and Epstein-Barr virus in subgingival plaque at periimplantitis, mucositis and healthy sites. A pilot study. Int J Oral Maxillofac Surg. 2011;40:271-6.

50. Douglas LJ. Medical importance of biofilms in Candida infections. Rev Iberoam Micol. 2002;19:139-43.

51. Douglas LJ. Candida biofilms and their role in infection. Trends Microbiol. 2003;11:30-6.

52. Baggi L, Di Girolamo M, Concetta $M$, et al. Microbiological evaluation of bacterial and mycotic seal in implant systems with different implant-abutment interfaces and closing torque values. Implant Dent. 2013;22:344-50.

53. Koutouzis T, Wallet S, Calderon $\mathrm{N}$, et al. Bacterial colonization of the implant-abutment interfaceusing an 
in vitro dynamic loading model. J Periodontol 2011;82:613-8.

54. Listgarten MA. Microorganisms and dental implants. J Periodontol. 1999;70:220-2.

55. Koutouzis T, Mesia R, Calderon N, et al. The effect of dynamic loading on bacterial colonization of the dental implant fixture-abutment interface: an in vitro study. J Oral Implantol. 2014;40:432-7.

56. Koutouzis T, Gadalla H, Lundgren T. Bacterial Colonization of the Implant-Abutment Interface (IAI) of Dental Implants with a Sloped Marginal Design: An invitro Study. Clin Implant Dent Relat Res. 2016;18:161-7.

57. Dongari-Bagtzoglou $A$, Kashleva $H$, Dwivedi $P$, et al. Characterization of mucosal Candida albicans biofilms. PLoS ONE. 2009;4:59-67.

58. Gow NA, van de Veerdonk FL, Brown AJ, et al. Candida albicans morphogenesis and host defence: discriminating invasion from colonization. Nat Rev Microbiol. 2011;10:112-22.

59. Alves CT, Wei XQ, Silva S, et al. Candida albicans promotes invasion and colonisation of Candida glabrata in a reconstituted human vaginal epithelium. J Infect. 2014;69:396-407.

60. Buu LM, Chen YC. Impact of glucose levels on expression of hypha-associated secreted aspartyl proteinases in Candida albicans. J Biomed Sci. 2014;21:22.

61. Lu Y, Su C, Solis NV, et al. Synergistic regulation of hyphal elongation by hypoxia, $\mathrm{CO} 2$, and nutrient conditions controls the virulence of Candida albicans. Cell Host Microbe. 2013;14:499-509.

62. Rudney JD, Jagtap PD, Reilly CS, et al. Protein relative abundance patterns associated with sucrose-induced dysbiosis are conserved across taxonomically diverse oral microcosm biofilm models of dental caries. Microbiome. 2015;3:69.

63. Dupuy AK, David MS, Li L, et al. Redefining the human oral mycobiome with improved practices in ampliconbased taxonomy: discovery of Malassezia as a prominent commensal. PloS One. 2014;9:90-9.

64. Vilela SFG, Barbosa JO, Rossoni RD, et al. Lactobacillus acidophilus ATCC 4356 inhibits biofilm formation by C. albicans and attenuates the experimental candidiasis in Galleria mellonella. Virulence. 2015;6:29-39.

65. Sousa V, Mardas N, Spratt D, et al. Experimental models for contamination of titanium surfaces and disinfection protocols. Clin Oral Implants Res. 2016;10:1233-42.

66. Krom BP, Kidwai S, ten Cate JM. Candida and other fungal species: forgotten players of healthy oral microbiota. J Dent Res. 2014;93:445-51.

67. Xu H, Sobue T, Thompson A, et al. Streptococcal coinfection augments Candida pathogenicity by amplifying the mucosal inflammatory response. Cell Microbiol. 2014;16:214-31.

68. Montelongo-Jauregui $D$, Srinivasan A, Ramasubramanian $A K$, et al. An in vitro model for Candida albicansStreptococcus gordonii biofilms on titanium surfaces. J Fungi (Basel). 2018;4.

69. Gokmenoglu C, Kara NB, Belduz M, et al. Evaluation of Candida albicans biofilm formation on various parts of implant material surfaces. Niger J Clin Pract. 2018;21:33-7.

70. Canabarro A, Valle C, Farias MR, et al. Association of subgingival colonization of candida albicans and other yeasts with severity of chronic periodontitis. J Periodontal Res. 2013;48:428-32.

71. Dongari-Bagtzoglou A, Kashleva $H$, Dwivedi $P$, et al. Characterization of mucosal Candida albicans biofilms. PLoS ONE. 2009;4:e7967.

72. Silva S, Negri M, Henriques M, et al. Adherence and bio fi Im formation of non-Candida albicans Candida species. Trends Microbiol. 2011;19:241-7.

\section{PEER REVIEW}

Not commissioned. Externally peer reviewed.

\section{CONFLICTS OF INTEREST}

The authors declare that they have no competing interests.

\section{FUNDING}

The authors declare that they have no competing interests. 
Figure 1: Radiograph of patient with peri-implantitis

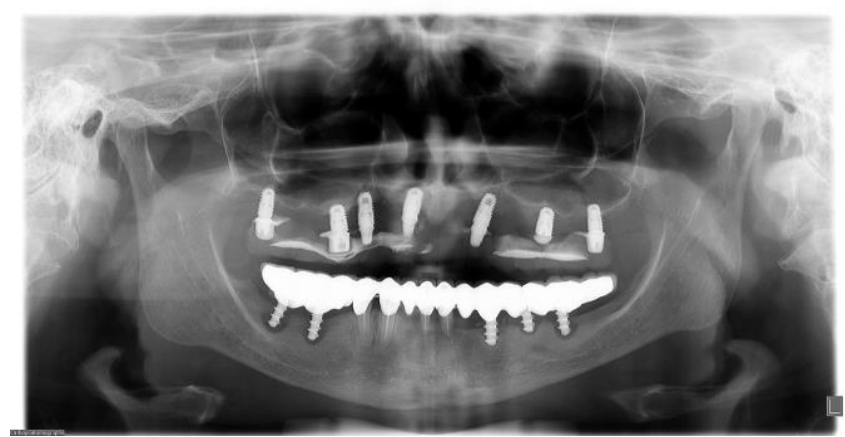

Figure 2: Prisma Flow Diagram

PRISMA 2009 “PERI-IMPLANTITIS" AND “CANDIDA" Flow Diagram

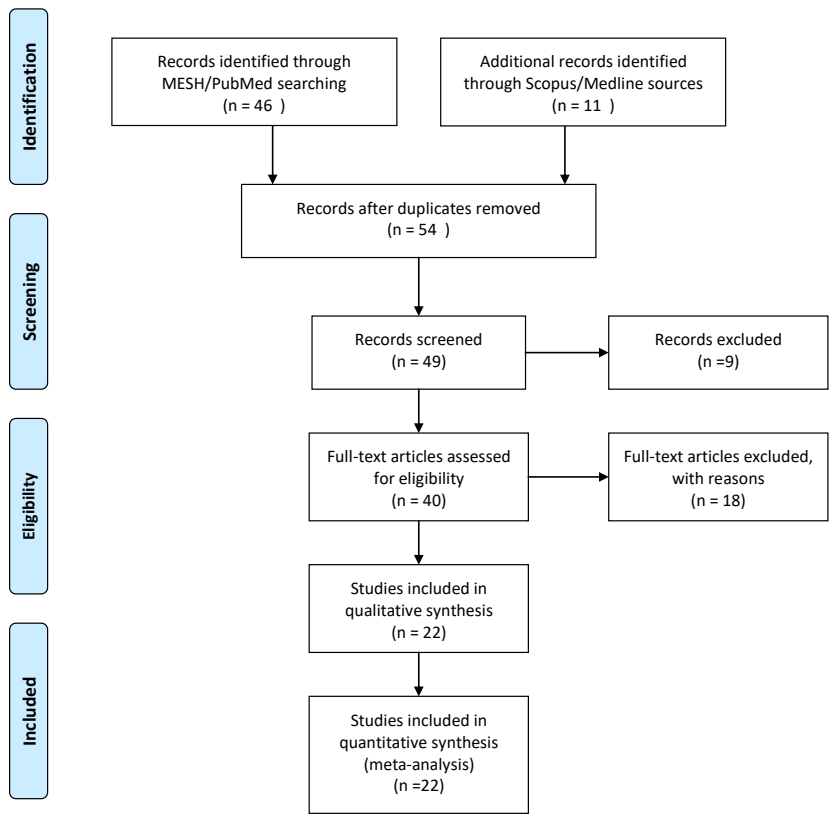

Figure 3: Peri-implant pocket formation and bone resorption

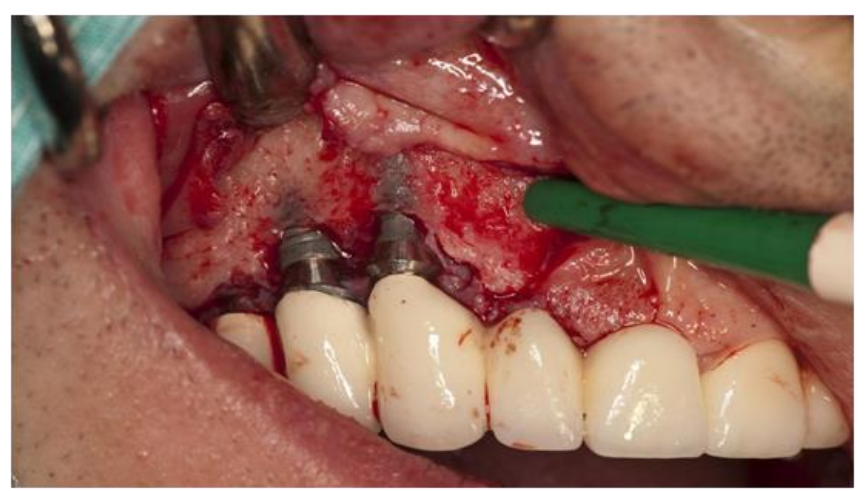

Figure 4: Bleeding on probing-BOP

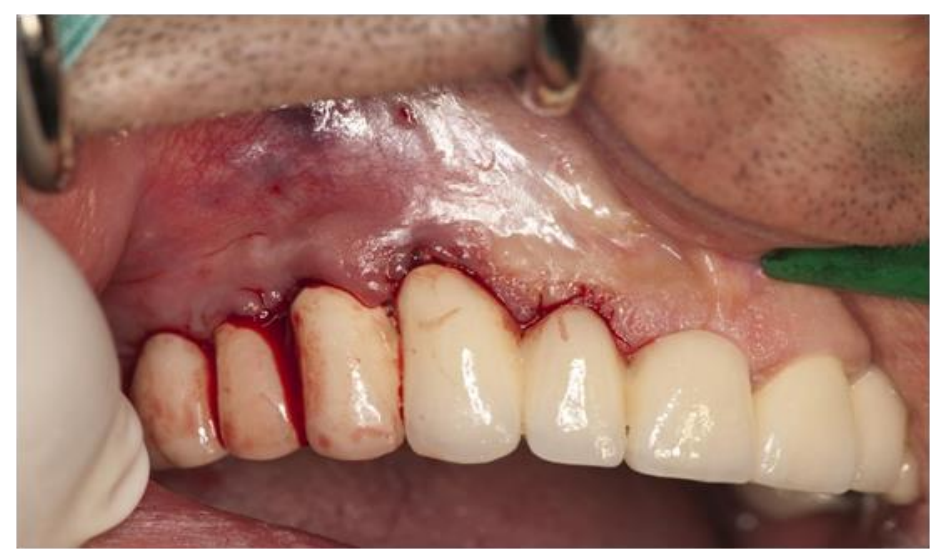

